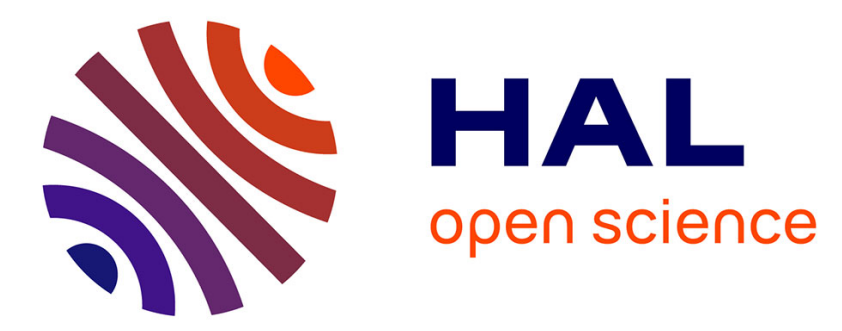

\title{
Seasonal variation in telomere dynamics in African striped mice
}

Francois Criscuolo, Neville Pillay, Sandrine Zahn, Carsten Schradin

\section{To cite this version:}

Francois Criscuolo, Neville Pillay, Sandrine Zahn, Carsten Schradin. Seasonal variation in telomere dynamics in African striped mice. Oecologia, 2020. hal-02985514

\section{HAL Id: hal-02985514 https://hal.science/hal-02985514}

Submitted on 2 Nov 2020

HAL is a multi-disciplinary open access archive for the deposit and dissemination of scientific research documents, whether they are published or not. The documents may come from teaching and research institutions in France or abroad, or from public or private research centers.
L'archive ouverte pluridisciplinaire HAL, est destinée au dépôt et à la diffusion de documents scientifiques de niveau recherche, publiés ou non, émanant des établissements d'enseignement et de recherche français ou étrangers, des laboratoires publics ou privés. 


\title{
Seasonal variation in telomere dynamics in African striped mice
}

\author{
Francois Criscuolo ${ }^{1}$, Neville Pillay ${ }^{2}$, Sandrine Zahn ${ }^{1} \&$ Carsten Schradin ${ }^{1,2}$
}

\footnotetext{
${ }^{1}$ Université de Strasbourg, CNRS, IPHC UMR 7178, F-67000 Strasbourg, France

${ }^{2}$ School of Animal, Plant and Environmental Sciences, University of the Witwatersrand, South Africa.
}

Key words: telomere length, telomere lengthening, seasonal variation, age, mice.

Corresponding authors: F. Criscuolo, francois.criscuolo@iphc.cnrs.fr 


\section{ABSTRACT}

Telomere shortening has been used as an indicator of aging and is believed to accelerate under harsh environmental conditions. This can be attributed to the fact that telomere shortening has often been regarded as non-reversible and negatively impacting fitness. However, studies of laboratory mice indicate that they may be able to repair telomere loss to recover from environmental harshness, as indicated by recent studies in hibernating rodents. We studied seasonal variation in telomere dynamics in African striped mice (Rhabdomys pumilio) living in a highly seasonal environment. In our annual species, individuals born in the moist spring (high food availability) need to survive the harsh dry summer (low food availability) to be able to reproduce in the following spring. We studied the effect of the harsh dry vs. the benign moist season on telomere dynamics. We also tested whether telomere length and changes in telomere length were associated with the probability that individuals disappeared form the population during the dry season. Male but not female stripped mice showed age-related telomere erosion. Telomeres were longer at the beginning of the dry season compared to the rest of the year. Telomeres increased significantly in length during the moist season. Neither telomere length at the onset of the dry season nor telomere loss over the dry season predicted whether or not individuals disappeared. In conclusion, our data suggest that seasonal attrition and restoring of telomeres also occurs in non-hibernating wild rodents living in hot food restricted environments. 
2 Telomeres are DNA sequences that cap the end of linear chromosomes and protect genome integrity

3 (Chan and Blackburn 2004). Telomeres erode progressively with cell replication and accumulation of

4 stress-derived damages (IImonen et al. 2008; Kotrschal et al. 2007; Olonikov 1973), which is considered

5 as one main indicator of the ageing rate of cells and of organisms. Hence, a straightforward initial

6 telomere-ageing hypothesis was that telomere length is shortened progressively with age, and that

7 faster shortening rate actually reflects senescence, and reduced individual fitness (Dantzer and Fletcher

8 2015; Salomons et al. 2009). Accordingly, both telomere length and telomere shortening have been

9 suggested to predict survival and/or longevity in different taxa (Fairlie et al. 2016; Heidinger et al. 2012;

10 Whittemore et al. 2019).

12 A potential causal role of telomeres on life history trajectories was supported by studies showing that

13 telomere length / shortening may reflect life stress effects like the costs of reproduction (IImonen et al.

14 2008; Kotrschal et al. 2007), and are related to immune status and response (Criscuolo et al. 2018b).

15 However, contradictory results have been published challenging the idea of continuous telomere

16 shortening with age or its link with higher mortality (Cerchiara et al. 2017; Martin-Ruiz et al. 2005; Seeker

17 et al. 2018). This highlighted a key element for our understanding of telomere role in animal ageing,

18 which is that the telomere - fitness relationships are indeed more complex than initially thought,

19 possibly because telomere dynamics evolved differently under distinct environmental pressures (Tian et

20 al. 2018). Whether telomeres are causal in ageing or rather just a biomarker of somatic maintenance is

21 still an open question (Simons 2015; Young 2018). This seems to be especially true for small mammals in

22 which telomere shortening is often not part of the cell replicative ageing process (Gorbunova et al. 2008;

23 Tian et al. 2018). For example, in laboratory mice, telomeres do not always shorten with cell divisions,

24 (Gomes et al. 2010; Gorbunova et al. 2008). However, other recent studies in laboratory mouse strains 
25 (e.g. C57BL/6 mice housed under ad libitum in standard laboratory conditions), showed some shortening

26 in telomere length as mice aged, at rates predictive of individual longevity (Vera et al. 2012). In addition,

27 sex differences exist in telomere length (Barrett and Richardson 2011), resulting in additional complexity

28 related to sex-specific telomere length inheritance or aging. Field studies of telomere dynamics on small

29 mammals to test these contrasting results obtained from controlled laboratory strains are mostly absent.

30 Even in other taxa than rodents, some studies found that telomeres may either be stable (cows:

31 (Seeker et al. 2018)) or even increase over time (great tits: (Atema et al. 2018)). In other mammals, such

32 as wild Soay sheep, telomere lengthening over an individual's lifetime was described (Fairlie et al. 2016)

33 (for a bird example, see also (Spurgin et al. 2018)). Remarkably, a recent study on hibernating rodents

34 have highlighted compensatory telomere lengthening when environmental conditions are becoming

35 favorable after winter (Hoelzl et al. 2016a). Three explanations have been proposed for an increase of

36 telomere length over time. Although (1) measurement errors or statistical adjustment in telomere length

37 assessment need to be checked (Nettle and Bateson 2017; Simons et al. 2014; Verhulst et al. 2013),

38 biological explanations have to be considered (Bateson and Nettle 2016), such as (2) variation in cell

39 population on which telomere lengths are measured, or (3) in activated telomere maintenance processes

40 (e.g. telomerase activity or alternative lengthening pathway) leading to actual elongation of telomere

41 ends (Blackburn 1991; Cesare and Reddel 2010; Criscuolo et al. 2018a), a process which may be

42 energetically costly (Hoelzl et al. 2016a; Nowack et al. 2019). If telomere size elongation in juvenile or

43 adult somatic cells is more common than initially believed (Fairlie et al. 2016; Haussmann et al. 2004;

44 Olsson et al. 2018), this would have important consequences for our understanding of how telomeres

45 interact with fitness-related traits. For instance, it may highlight why long telomeres correlate better

46 with individual fitness than short telomeres (Bauch et al. 2014). Importantly, we should test whether

47 there is further evidence for an increase in telomere length in individuals living under different harsh

48 environmental conditions than studied so far and whether this is related to fitness. 
In wild-derived house mice strains (Mus musculus) kept under laboratory conditions, individuals

50 showed accelerated telomere loss with immune, reproductive or social stress but non-significant

51 relationships with mortality (IImonen et al. 2008; Kotrschal et al. 2007). Thus, one important emerging

52 question is whether the idea that the shortening of telomeres under environmentally harsh conditions is

53 long-lasting (De Punder et al. 2018; Reichert et al. 2014), or whether shortened telomeres can remain

54 stable in size or even increase when environmental conditions become favorable. Whether telomere

55 lengthening is a selected maintenance process improving individual fitness via increased lifespan, for

56 example in hibernating mammals (Hoelzl et al. 2016b; Turbill et al. 2012), remains an unanswered

57 question. To our knowledge, only four published studies described seasonal variation in telomere length

58 (one on small wild mammals) (Fairlie et al. 2016; Hoelzl et al. 2016a; Quirici et al. 2016b; Stier et al.

59 2014). Two studies approached this question indirectly through cross-sectional sampling, assessing

60 differences in telomere length between individuals experiencing different environments during growth

61 or reproduction (Quirici et al. 2016a; Stier et al. 2014). Studies in Soay sheep and edible dormice

62 provided some evidence that changes in telomere length are more related to seasonal variation in

63 environmental conditions (like high population densities and feeding conditions before and/or during the

64 winter) than to age (Fairlie et al. 2016; Hoelzl et al. 2016a).

65 To better understand how telomere dynamics are affected by environmental harshness,

66 longitudinal studies are needed, where individuals are sampled repeatedly under different

67 environmental conditions. Here, we investigated telomere dynamics in African striped mice (Rhabdomys

68 pumilio). Striped mice inhabit a highly seasonal environment with high food abundance in the moist

69 spring being followed by the food restricted harsh dry season in summer. We sampled individuals

70 repeatedly, at the onset of the dry season (January), after they experienced 3 months of harshness in the

71 middle of the dry season (March), 7 months after they experienced harshness at the end of the onset of

72 the moist season (July), and at the end of the favourable moist season with high food abundance 
73 (October). We predicted telomere shortening to be faster during the harsh food-restricted dry season

74 than during the favourable moist season, and that telomere length at the onset of the dry season is

75 related to disappearance risk of individuals, which we used as proxy for dry season survival and thus

76 fitness.

77 
MATERIAL AND METHODS

\section{Study species}

80 The striped mouse is an omnivorous annual species: individuals are born in the moist spring (August to

81 December) with peak food availability, then have to survive the following hot summer dry season

82 (January to May) with very low food availability, before reproducing in the following spring; less than $1 \%$

83 of striped mice survive to reproduce in a second spring (Schradin et al. 2012). Depending on the

84 harshness of the dry season, $1 \%$ to $50 \%$ of the striped mice survive the dry season to reproduce, such

85 that dry season survival is a key determinant of individual fitness. In the breeding season, striped mice

86 can live solitarily but more often live in communally breeding groups with 2-4 breeding females and 1

87 breeding male, and adult offspring remain philopatric, such that all striped mice live in social groups

88 during the dry season (Schradin et al. 2010; Schradin et al. 2019).

\section{Data collection}

91 The study was conducted in Goegap Nature Reserve in South Africa (S 29 41.56, E 18 1.60). Goegap lies

92 within the semi-desert Succulent Karoo biome, which is characterized by cold and moist winters followed

93 by spring with high food abundance and hot dry summers with low food abundance. During the current

94 study, food availability measured as the number of food plant species per $4 \mathrm{~m}^{2}$ monitoring plot changed

95 from 2.8 in January to 2.0 in March, 6.4 in August (after the July sampling), and 3.6 in October. Our field

96 site was 7 ha and contained 12 social groups. Because the population was monitored throughout the

97 year, we knew all individuals present on the field site, their life history, and their group affiliation

98 (Schradin et al. 2019). Trapping continued even after our study such that we knew which individuals

99 disappeared during the study and did not re-appear afterwards. During our normal monitoring, every

100 group was trapped for 3 days 2 to 4 times every month (i.e. 6 to 12 days per month). 
101 Tail tissue can be used to evaluate somatic telomere dynamics and are representative of telomere 102 dynamics of overall body soma (Daniali et al. 2013). Collecting tail tissue has the advantage of being non103 lethal and allowing repeated sampling, which is essential for longitudinal studies. We repeatedly 104 collected tissue samples (1-2mm tail snips) from all individuals present on the field site ( $n=80$, age $11-$ 105737 days) during extensive trapping sessions (always for 7 days) in 2018 at: (i) the beginning of January 106 (onset dry season); (ii) March (middle dry season); (iii) End of July, beginning of August (onset of the 107 moist and breeding season); and (iv) October (end of the moist / breeding season). Individuals were born 108 in the moist season (August and December) in $2016(n=9)$ or $2017(n=48)$, with 14 individuals being born 109 between January and July 2018. Season of birth was unknown for 9 immigrants born in 2016 ( $n=2), 2017$ $110(n=6)$ and undefined $(n=1)$. Tail clips were stored in 95\% ethanol and transported to Strasbourg, France, 111 for analysis.

112 For the onset of the dry season (January), we had samples from 54 individuals (29 females, 25

113 males, age 15-501 days). For the onset of the moist season (end of July), we had samples from 26

114 individuals (16 females, 10 males, age 9-652 days). In addition, intra-individual changes in telomere 115 length was evaluated through repeated tissue sampling of the same individual in (i) January and March 116 for 36 individuals (21 females, 15 males, individual variation in telomere dynamics over the dry season), 117 (ii) July and October for 26 individuals (16 females, 10 males, individual variation in telomere dynamics 118 over the moist season), and (iii) 6 individuals sampled monthly during all four months (Figure 1).

119 Fieldwork and tissue sampling were carried out under the necessary licenses. All data were 120 collected following protocols approved by the Animal Ethics Screening Committee of the University of 121 the Witwatersrand (AESC 2012/37/2A, AESC 2014/40/B). 
124 Striped mice DNA was extracted from tail tissue using Nucleospin Tissue kit (Macherey-Nagel, Düren,

125 Germany). DNA quality and concentration were assessed with a Nano-Drop spectrophotometer 126 (NanoDrop Technologies, Thermo Fisher Scientific) and diluted to the concentration of $2.5 \mathrm{ng} / \mathrm{mL}$.

127 Relative telomere length was measured in striped mice on extracted DNA from tail tissue, using the

128 methodology of real-time qPCR that originated from the work of Cawthon and collaborators on human

129 samples (Cawthon 2002). For our study, the qPCR amplification protocol has been adapted as follows:

130 (i) qPCR gives us as a final results a ratio (T/S) of amplification cycles (Cq) of the telomere sequence (T)

131 and of a genomic gene sequence (S) that must be specific or preferably a non-variable copy number

132 (non-VCN) gene (Smith et al. 2011). Final T/S values were calculated by taking into account each plate

133 efficiencies, following (Pfaffl 2001). For the present study, we designed amplification primers for a region

134 using aligned sequences of PGK1 genes from other closely related organisms extracted from the NCBI

135 data base (Huchon et al. 2017). We used a 150 bp portion of the phosphoglycerate gene (PGK1), which

136 was found non-variable in copy number within our population of striped mice (Cq values ranged

137 between $24-25.6$ for $90 \%$ of the samples). Primer sequences for the non-VCN gene were: Forward

138 primer: 5'-CGGAGACACCGCCACTTG-3' and Reverse primer: 5'-AAGGCAGGAAAATACTAAACAT-3'. The

139 forward and reverse primers for the telomere sequence were: 5'-

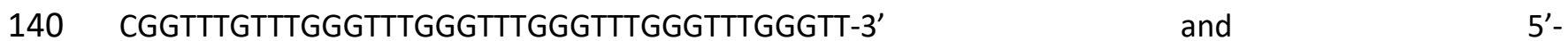

141 GGCTTGCCTTACCCTTACCCTTACCCTTACCCTTACCCT-3', respectively.

142 (ii) Amplifications of $\mathrm{T}$ and $\mathrm{S}$ were done on distinct 96-wells plates due to differences in amplification

143 temperatures using an automated thermocycler (Master-cycler Realplex; Eppendorf, Hamburg,

144 Germany). The reactions conditions were set as follows: for the telomere amplification, $95^{\circ} \mathrm{C}$ for $2 \mathrm{~min}-$

145 followed by 30 cycles of $95^{\circ} \mathrm{C}$ for $15 \mathrm{sec}, 56^{\circ} \mathrm{C}$ for $15 \mathrm{sec}, 72^{\circ} \mathrm{C}$ for $30 \mathrm{sec}$; for the PGK1 amplification, $95^{\circ} \mathrm{C}$

146 for $2 \mathrm{~min}$ - followed by $30 \mathrm{cycles}$ of $95^{\circ} \mathrm{C}$ for $15 \mathrm{sec}, 60^{\circ} \mathrm{C}$ for $15 \mathrm{sec}, 72^{\circ} \mathrm{C}$ for $30 \mathrm{sec}$. All amplification

147 runs were ended by a melting curve program (steady increase in amplification temperature from $56^{\circ} \mathrm{C}(\mathrm{T})$ 
148 or $\left.60^{\circ} \mathrm{C}(\mathrm{S})\right)$ to verify the absence of non-specific amplification events (i.e. lack of specificity of the

149 primers or primer-dimer artefacts, see below). A negative control (without DNA) was also present on 150 each plate to check for potential contamination.

151 (iii) Amplifications were performed with $5 \mathrm{ng}$ of DNA (2 uL) per well, in a final volume of $10 \mathrm{uL}$ containing

$1525 \mathrm{uL}$ of GoTaq qPCR mix (Promega, Madison, WI, USA), 0.5 uL of each primers at an initial concentration 153 of $5 \mathrm{nM}$ and $2 \mathrm{uL}$ of ultra-pure water.

154 (iv) Samples were amplified in duplicates, on 4 different runs (each comprising 1 telomere plate and 1 155 PGK1 plate). Each 96-wells plate included a dilution curve of the same randomly-chosen reference 156 sample, serially diluted from 10 to $0.625 \mathrm{ng} / \mathrm{mL}$ of DNA, to check for consistency in amplification 157 efficiency among plates ( $r^{2}$ of the dilution curves were comprised between $0.931-0.998$ (telomere) and $1580.995-0.998$ (PGK1)). In addition, 5 samples were repeated over all plates. Mean amplification 159 efficiencies were of $96.0 \pm 0.44 \%$ for PGK1 and $97.8 \pm 0.97 \%$ for telomere. We did not include any plate 160 effect in our models since there was no indications for an inter-plate variation in the T/S ratio values 161 (Linear model, estimates $-0.002 \pm 0.017, t=-0.13, P=0.896$ ).

\section{3 qPCR repeatabilities and effect of storage time}

164 As suggested by (Nettle et al. 2019), we evaluated the repeatability of our measures using intra-class 165 correlation coefficients (ICC, $R$ package ICC, (Wolak et al. 2012)) both for intra-plate (duplicates) and 166 inter-plates variability in T/S ratio (see also (Eisenberg 2016)). Intra-plate ICC was of 0.864 and inter-plate 167 ICC was of 0.836 (Cicchetti 1994). We also checked whether ICC varied with time of storage, i.e. time of 168 sampling (from January to October): all samples were analysed together in May 2018, such that samples

169 from January had the longest storage time and those samples from October had shortest storage time.

170 Measurement repeatability (intra-individual) did not change with time from January (ICC $=0.851)$, March

171 (0.835), July (0.769) and October 2018 (0.901). In addition, we found that T/S ratios were correlated 
172 within individuals measured both in January and March $\left(n=35, t_{1,34}=2.413, P=0.021\right)$, and both in July

173 and October $\left(n=30, t_{1,29}=2.198, P=0.036\right.$; see Figure1 in ESM 1). Additional $q P C R$ methodological 174 details are presented in ESM1.

\section{Statistical analysis}

177 Data were analysed using R version 3.5.1 (R Foundation for statistical Computing Platform, 2018), using 178 the packages Ime4 (function Imer) (Bates et al. 2014) and Factominer (Lê et al. 2008). We tested for 179 normality with both a Shapiro-Wilk's test and QQ plots distribution (fitdistrplus package, (Delignette180 Muller and Dutang 2015)). We used a Linear Mixed Model (LMM) to analyse the relationship between 181 telomere length ( $n=154$ measures) and the following explanatory variables: Age, sex, and season and all 182 interactions. Season was coded in 4 categories : beginning of the dry season (January), middle of the dry 183 season (March), beginning of the moist season (July) and middle of the moist season (October). So, our 184 statistical analysis considers the 4 sampling points and tested for differences among 4 season categories.

185 Posthoc multiple comparisons among the 4 season categories were conducted using the function glht 186 from the multcomp package (Hothorn et al. 2008). Individual ID was included as random factor (to 187 control for repeated sampling). Because age, body mass and body size are interdependent, we also used 188 a principal component analysis (PCA) to merge those variables into one PC axis (ESM2). PCA1 turned out 189 to be non-significant in all models, so we kept only Age as a fixed factor in the final analysis. The date of 190 birth was initially used as a fixed factor when testing variance in individual relative telomere length, but 191 it was not significant (LMM, estimates $0.002 \pm 0.001, t=1.556, \mathrm{P}=0.124)$ and not considered in our final 192 models. Individual changes in telomere length over the dry and moist seasons were tested using paired $t$ 193 tests. To test the predictive value of relative telomere length on disappearance risk of individual striped 194 mice from the population (Vuarin et al. 2019), we used a linear mixed model with binomial distribution 195 of the survival variable ( 0 and 1 , the latter indicating the presence of the individual). Individuals were 
196 regarded as not having disappeared when they were still trapped in July or afterwards (monthly trapping

197 of groups continued for 1.5 years). Of the 54 individuals sampled in January, 19 survived until July and 35

198 disappeared. July was chosen as the censoring date, since this is when breeding dispersal peaks, such

199 that most cases of disappearance that occur before this time can be assumed to be due to mortality

200 (Vuarin et al. 2019). Explanatory variables included in the models were telomere lengths measured in

201 January, March and July ( $n=52$ measures, with Individual ID as random factor). In addition, telomere

202 length rate of change (i.e. the within individual differences in telomere lengths measured within the dry

203 season or TROC, $\mathrm{n}=92$ measures) was tested separately. Using the correction for the regression to the

204 mean (RtM) effect ((Verhulst et al. 2013), ESM4) or using, as we present in the main text, uncorrected

205 TROC with the initial telomere length as a covariate (Bateson et al. 2019; Hoelzl et al. 2016b) did not

206 change the output of the models. We choose to present models obtained after model selection using

207 the Akaike Information Criterion corrected for small sample sizes (Mumin R package, (Barton 2020),

208 ESM3).

209 
211 There was an overall significant variation in relative telomere length over the seasons (Table 1, Figure 2).

212 Posthoc Tukey contrasts indicated that, overall, relative telomere lengths were longest at the start of the

213 dry season in January and shortest in March and July. Relative telomere lengths were significantly longer

214 in October than in July $(P=0.035$; while there was no significant difference between March and October,

$215 P=0.994$ ). Individual telomere dynamics (Figure 3) demonstrated that, during the dry season, telomere

216 length of most individuals declined (paired $t$-test, $t_{35}=3.486, \mathrm{P}=0.001$, mean difference in relative

217 telomere length $=-0.238 \mathrm{~T} / \mathrm{S}$ ratio) whereas during the moist season, telomere lengths of most

218 individuals increased (paired $t$-test, $t_{31}=4.373, \mathrm{P}<0.001$, mean difference in relative telomere length $=$ $2190.170 \mathrm{~T} / \mathrm{S}$ ratio).

220 The difference in relative telomere length between sexes depended on age (interaction term Age

$221 \times$ Sex: $P=0.031$, Table 1). Telomeres of males shortened significantly during ageing while female

222 telomeres did not (Figure 4, linear regression, males: $\mathrm{df}=62, \mathrm{t}=-2.91, \mathrm{P}=0.005$; females: $\mathrm{df}=88, \mathrm{t}=-$

$2230.09, P=0.930)$.

224 Individual disappearance risk during the dry season (i.e. from January to July) was not 225 significantly predicted by the relative telomere length measured at the beginning of the dry season $(n=$ 226 52, Table 2A) nor by TROC within the dry season (January to March, Table 2B). TROC corrected for the 227 regression to the mean stayed non-significant for predicting disappearance risk $(0.956 \pm 0.866, z=0.110$, $228 P=0.912)$. None of the other explanatory variables (sex, age, and interaction terms, all $P>0.308$ ) 229 predicted individual disappearance. 
232 Here we showed that (i) the degree of telomere length degradation differed between the harsh dry and

233 the favorable moist season in African striped mice, and (ii) that this effect appeared independent of an

234 age effect which was only evident in males. In fact, on average, telomere length even increased in

235 individuals from July to October (more so in females), demonstrating that the telomere loss during the

236 preceding dry season cannot be simply explained by age (Figure 3). This indicates that environmental

237 harshness influences telomere dynamics: telomeres degrade under harsh conditions but can increase

238 afterwards, at least in females. Thus, our study indicates that a small mammal living under harsh

239 conditions characterized by heat and low food abundance shows similar telomere dynamics as small

240 hibernating mammals after winter but can be subsequently restored, at least partially, during periods of

241 higher food availability (Hoelzl et al. 2016a).

242 Telomere shortening might indicate energetic costs (Criscuolo et al. 2018b; Ilmonen et al. 2008;

243 Nettle et al. 2015; Reichert et al. 2014). In our study, food was two times more abundant during the peak

244 of the moist season than during the dry season, such that the dry season was much harsher than the

245 moist season. Accordingly, telomeres shortened significantly during the dry season. Physiological factors

246 that are suspected to negatively affect telomeres in other species include high metabolic rate via

247 increased oxidative stress ((Reichert and Stier 2017) but see (Boonekamp et al. 2017) and (Turbill et al.

248 2012)) and corticosterone levels ((Haussmann et al. 2012; Tissier et al. 2014) but see (Gil et al. 2019)).

249 Also, in striped mice, the food restricted dry season triggers several physiological mechanisms (Rimbach

250 et al. 2016; Schradin 2008a; Schradin 2008b; Schradin et al. 2014), enabling them to reduce both resting

251 metabolic rate and daily energy expenditure (Rimbach et al 2018a). Metabolic rate and corticosterone

252 levels in striped mice are increased during the moist season (Rimbach et al. 2018a; Rimbach et al. 2018b;

253 Schradin 2008c) which would predict a decrease in telomere length, while in opposite we observed an

254 increase. Instead, the low energy availability in the dry season might lead to a decreased investment in 
255 cell maintenance and telomere degradation. In the harsh summer, striped mice might rather invest in

256 mechanisms that improve immediate dry season survival while increased food abundance in the

257 subsequent spring favours energy investment into telomere maintenance.

258 We found age-related telomere erosion in males but not in females. Males also tended to have 259 slightly longer telomeres than females (Table $1, \mathrm{P}=0.076$ ). If males start their yearly cycle with longer

260 telomeres (Figure 3), this may give a mechanistic explanation for faster shortening thereafter, since long

261 telomeres are expected to be more susceptible to damage and less to maintenance than short telomeres

262 (Bauch et al. 2014). A trade-off based effect due to sex-specific investment in reproduction vs. telomere

263 maintenance should be explored in the future, based, for instance, on an earlier reproductive investment

264 in males during the dry season (Schradin and Pillay 2005). Further, females may better protect their

265 telomeres or invest in soma maintenance in order to transfer longer telomeres to the next generation, as

266 suggested for another ageing-related mechanism, oxidative stress, in two distinct mammal species

267 (Mungos mungo and Urocitellus columbianus, (Viblanc et al. 2018; Vitikainen et al. 2016). Future studies

268 should investigate sex specific telomere dynamics depending on sex specific investment into

269 reproduction and whether the shield hypothesis protecting offspring from maternal oxidative stress

270 (Blount et al. 2016) extends to telomere inheritance.

271 Only $37 \%$ of the individuals sampled at the onset of the dry season were still present on the field

272 site after the dry season, the rest having disappeared. In our current study, individuals with shorter

273 telomeres were not more likely to disappear during the food restricted dry season. This leads to the

274 hypothesis that telomere length in striped mice is uncoupled from short-term survival because of high

275 extrinsic mortality risks. An alternative may be that, like other small rodents (Seluanov et al. 2007),

276 striped mice maintain a high telomerase activity throughout their lives and consequently telomere

277 length is not a good cell ageing marker. However, in wild mice strains (Mus musculus (Criscuolo et al.

278 2018b; Kotrschal et al. 2007)) and in a laboratory study conducted on Sudanian grass rat (Arvicanthis 
279 ansorgei, (Grosbellet et al. 2015)), the rate of telomere shortening increased with stress caused by

280 circadian desynchronization. Telomere shortening in mice should then be more closely related to survival

281 (IImonen et al. 2008), since a faster telomere loss may reflect a concomitant deterioration of the

282 organism's functioning (i.e. as an intrinsic ageing process, (Harris et al. 2016; Whittemore et al. 2019)).

283 We did not find such a relationship since individuals with increased telomere shortening during the dry

284 season were not more likely to disappear. In future, we need more data to test whether telomere length

285 is correlated with reproductive success in striped mice.

286 It is currently widely debated whether reported increases in telomere length represents

287 measurement errors or are of biological relevance (Bateson and Nettle 2016; Steenstrup et al. 2013). To

288 date, negative and positive variation in telomere length over life have been found in free-living mammals

289 and birds sampled longitudinally (Fairlie et al. 2016; Spurgin et al. 2018), illustrating the potential

290 biological relevance of telomere lengthening. In striped mice, telomeres even increased in many

291 individuals during the moist season (Figure 3). Although a long-term study with several dry and moist

292 seasons differing in harshness is needed to definitively show an effect of harshness on telomere

293 dynamics, the observed lengthening of telomeres raises questions about both its ultimate function (i.e.

294 link with reproductive success) and proximate mechanism (i.e. seasonal changes in telomerase activity or

295 changes in the rate of cell renewal). It is important to note that even though we were not able to

296 statistically test for true lengthening (which needs at least 3 repeated samples, (Simons et al. 2014),

297 because we used repeated tail sampling for telomere measurements, attributing telomere lengthening

298 to a change in cell population is less likely than in studies using repeated blood sampling. One ultimate

299 hypothesis may be related to breeding. Since the moist season is also the breeding season for striped

300 mice, the lengthening of somatic telomeres may improve reproductive success either because it is

301 associated with enhanced adult physiological processes or because it ensures better offspring quality.

302 Therefore, elongating telomeres in breeding adults may be of key importance for fitness. Such an 
303 increase in telomere length was previously found in the edible dormouse (Glis glis), also during the active 304 breeding season (Turbill et al. 2013). Our study sheds lights on the fact that telomere elongation is not

305 specific to hibernating rodents. Itsuggests that telomere dynamics change seasonally in a sex specific 306 way in free-living striped mice, and that, as previously found in hibernating small mammals (Hoelzl et al.

307 2016a; Nowack et al. 2019), telomeres can even lengthen after a harsh season when environmental

308 conditions become favourable. This indicates that telomere dynamics are plastic and future studies need 309 to focus on the ultimate function and proximate mechanisms of increasing telomere length in striped 310 mice specifically and free-living animals generally.

311

\section{ACKNOWLEDGEMENTS}

313 This study was supported by the Succulent Karoo Research Station, the University of the Witwatersrand, 314 and the CNRS. We are grateful to Goegap Nature Reserve and for the help of several field managers and 315 assistants. Data are available online at figshare doi: $x x x x x x$. 


\section{$318 \quad$ Figure1}

319 Schematic representation of the repeated sampling design of the study. In total, we collected 154

320 samples from 80 individuals (starting with 54 mice in January and adding 26 mice in July), but not all

321 individuals were sampled repeatedly. 36 individuals were sampled both at the start (January) and the

322 middle (March) of the dry season. 32 individuals were sampled both at the start (July) and the middle

323 (October) of the moist season. Altogether 6 individuals were sampled during all four months.

\section{Figure 2}

325 Year-round variation in relative telomere length in adult striped mice (156 samples from 80 individuals).

326 Relative telomere length was repeatedly measured in 36 individuals over part of the dry season (two

327 sampling sessions in January and March) and in 32 individuals over the moist season (July and October).

$328 *$ indicates significant levels of posthoc Tukey contrasts: $* * *<0.001, * *<0.01, *<0.05$. Boxplots

329 indicate minimum and maximum, median (black line), first and third quartile and mean (diamonds)

330 values. See text for details.

\section{Figure 3}

333 Individual variation in relative telomere length in male (left panel) and female (right panel) adult striped

334 mice over the beginning and middle of the dry season (January and February, black circles, 36

335 individuals) and beginning and middle of the moist season (July and October, grey circles, 26

336 individuals). Increases in telomere length were found in 24 of 32 individuals in the moist season.

337 Numbers for the dry season was 11 of 36 individuals. Dashed lines indicate the 6 individuals that were 338 sampled 4 times over the year. 
341 Relative telomere length of striped mice in relation to sex over the entire study period. The Sex $x$ Age

342 interaction was significant $(P=0.031$, Table 1$)$, indicating that males underwent an age-related telomere

343 erosion (linear regression, $\mathrm{P}=0.005$ ) while females did not (linear regression, $\mathrm{P}=0.930$ ). See text for

344 details. Confidence intervals $95 \%$ are indicated in grey.

345 
347 Table 1: Linear mixed model explaining the effects of season (coded using the 4 monthly sampling

348 points, January / March for the dry season and July / October for the moist season), age, and sex on

349 individual relative telomere length in wild striped mice. The model encompasses repeated telomere data

350 from individuals sequentially sampled within seasons (individual ID as random factor) but includes all

351 individual measurements (in total 154 telomere measurements among 80 individuals). Seasons are

352 defined as dry (January and March) and moist (July and October, see figure 1). Significant fixed effects (in

353 bold) are considered at $\mathrm{P}<0.05$ and tendencies (in italics) are considered at $\mathrm{P}<0.1, \mathrm{P}$ values being

354 obtained using the anova $\mathrm{R}$ function. The model presented was selected based on AICc values. Posthoc

355 comparisons were done using the multcomp R package.

356

\begin{tabular}{|c|c|c|c|c|}
\hline Response variable: Relative telomere length & Estimates \pm SE & $d f$ & $Z$ value & $\mathbf{P}$ \\
\hline $\begin{array}{lc}\text { Random factors } & \begin{array}{c}\text { Individual ID } \\
\text { Residual variance }\end{array}\end{array}$ & $\begin{array}{l}0.019 \pm 0.014 \\
0.063 \pm 0.251\end{array}$ & & & \\
\hline \multicolumn{5}{|l|}{ Fixed factors } \\
\hline Intercept & $0.935 \pm 0.057$ & 128.2 & 16.275 & $<0.001$ \\
\hline $\operatorname{Sex}(M)$ & $0.150 \pm 0.084$ & 100.6 & 1.794 & 0.076 \\
\hline Age & $0.001 \pm 0.001$ & 114.4 & 0.436 & 0.664 \\
\hline Sex $x$ Age & $-0.001 \pm 0.001$ & 100.8 & -2.192 & 0.031 \\
\hline Season & $-0.199 \pm 0.062$ & 104.9 & 10.723 & $<0.001$ \\
\hline Tukey Contrast posthoc & & & $Z$ value & $\mathbf{P}$ \\
\hline January - March & $0.181 \pm 0.056$ & & 3.263 & 0.006 \\
\hline January - July & $0.334 \pm 0.063$ & & 5.280 & $<0.001$ \\
\hline January - October & $0.164 \pm 0.063$ & & 2.593 & 0.047 \\
\hline March - July & $0.152 \pm 0.068$ & & 2.234 & 0.113 \\
\hline March - October & $-0.018 \pm 0.068$ & & -0.259 & 0.994 \\
\hline July - October & $-0.170 \pm 0.063$ & & -2.692 & 0.035 \\
\hline
\end{tabular}


360 Table 2: Predictors of survival of striped mice until the beginning of the 2018 breeding season (i.e. July).

361 A generalized linear model was used, following a binary distribution of individual survival $(0=$

362 disappearance) using (A) the individual telomere lengths measured at the start of the dry season (i.e.

363 January) and (B) the rate of change in telomere length (TROC) over the dry season (i.e. January - March).

364 Results were also not significant when using TROC corrected for the regression to the mean effect (see

365 Results). Estimates \pm SE are given for males vs. females. Significant fixed effects (in bold) are considered

366 for $\mathrm{P}<0.05$. The models presented here were selected from AICc values.

\begin{tabular}{|c|c|c|c|}
\hline A. Response variable: Survival & Estimates $\pm \mathrm{SE}$ & $Z$ value & $\mathbf{P}$ \\
\hline Random factors Individual ID & $5276 \pm 72.63$ & & \\
\hline \multicolumn{4}{|l|}{ Fixed factors } \\
\hline Intercept & $-18.899 \pm 6.633$ & -2.849 & 0.004 \\
\hline Relative telomere length ( $\mathrm{T} / \mathrm{S}$ ratio) & $0.664 \pm 6.218$ & 0.107 & 0.915 \\
\hline Sex (M) & $-9.389 \pm 23.168$ & -0.405 & 0.685 \\
\hline Age & $-0.063 \pm 2.902$ & -0.180 & 0.798 \\
\hline Sex $x$ Age & $0.039 \pm 0.052$ & 0.749 & 0.454 \\
\hline Relative telomere length $\times$ Sex & $6.063 \pm 14.284$ & 0.424 & 0.671 \\
\hline B. Response variable: Survival & Estimates $\pm \mathrm{SE}$ & $Z$ value & $\mathbf{P}$ \\
\hline Random factors Individual ID & NA & & \\
\hline \multicolumn{4}{|l|}{ Fixed factors } \\
\hline Intercept & $-1.070 \pm 1.703$ & -0.629 & 0.530 \\
\hline Telomere rate of change ( $\mathrm{T} / \mathrm{S}$ ratio) & $0.390 \pm 1.926$ & 0.203 & 0.839 \\
\hline Age & $0.002 \pm 0.003$ & 0.781 & 0.435 \\
\hline Sex (M vs. F) & $-2.791 \pm 1.395$ & -2.001 & 0.045 \\
\hline Initial relative telomere length & $1.144 \pm 1.900$ & 0.602 & 0.547 \\
\hline Age $x$ Sex & $0.017 \pm 0.012$ & 1.363 & 0.173 \\
\hline
\end{tabular}

367

368 
Atema E, Mulder E, Van Noordwijk AJ, Verhulst S (2018) Ultra-long telomeres shorten with age in nestling great tits but are static in adults and mask attrition of short telomeres. Molecular Ecology Resources 19:648-658

Barrett ELB, Richardson DS (2011) Sex differences in telomeres and lifespan. Aging Cell 10:913921. doi: 10.1111/j.1474-9726.2011.00741.x

Barton K (2020) MuMIn: Multi-Model Inference. . R package version 1.43.17. doi: https://CRAN.R-project.org/package=MuMIn

Bates D, Mächler M, Bolker B, Walker S (2014) Fitting linear mixed-effects models using Ime4. arXiv preprint arXiv 1808.00864:1406.5823

Bateson M, Eisenberg DTA, Nettle D (2019) Controlling for baseline telomere length biases estimates of the rate of telomere attrition. Royal Society Open Science 6:190937. doi: 10.1098/rsos.190937 10.6084/m9.figshare.c

Bateson M, Nettle D (2016) The telomere lengthening conundrum - it could be biology. Aging Cell 16:312-319

Bauch C, Becker PH, Verhulst S (2014) Within the genome, long telomeres are more informative than short telomeres with respect to fitness components in a long-lived seabird. Molecular Ecology 23:300-310. doi: 10.1111/mec.12602

Blackburn EH (1991) Structure and function of telomeres. Nature 6319:569

Blount JD, Vitikainen EIK, Stott I, Cant MA (2016) Oxidative shielding and the cost of reproduction. Biological Reviews 91:483-497. doi: 10.1111/brv.12179

Boonekamp JJ, Bauch C, Mulder E, Verhulst S (2017) Does oxidative stress shorten telomeres? Biology Letters 13:20170164

Cawthon RM (2002) Telomere measurement by quantitative PCR. Nucleic Acids Research 30:e47

Cerchiara JA, Risques RA, Prunkard D, Smith JR, Kane OJ, BOERSMA PD (2017) Telomeres shorten and then lengthen before fledging in Magellanic penguins (Spheniscus magellanicus). Aging 9:487-493

Cesare AJ, Reddel RR (2010) Alternative lengthening of telomeres: models, mechanisms and implications. Nature Reviews Genetics 11:319-330. doi: 10.1038/nrg2763

Chan SRWL, Blackburn EH (2004) Telomeres and telomerase. Philosophical Transactions of the Royal Society B: Biological Sciences 359:109-122. doi: 10.1098/rstb.2003.1370

Cicchetti DV (1994) Guidelines, criteria, and rules of thumb for evaluating normed and standardized assessment instruments in psychology. Psychological Assessment 6:284290. doi: 10.1037/1040-3590.6.4.284

Criscuolo F, Smith S, Zahn S, Heidinger BJ, Haussmann MF (2018a) Experimental manipulation of telomere length: does it reveal a corner-stone role for telomerase in the natural variability of individual fitness? Philosophical Transactions of the Royal Society B: Biological Sciences 373:20160440. doi: 10.1098/rstb.2016.0440 10.6084/m9

Criscuolo F, Sorci G, Behaim-Delarbre M, Zahn S, Faivre B, Bertile F (2018b) Age-related response to an acute innate immune challenge in mice: proteomics reveals a telomere 
maintenance-related cost. Proceedings of the Royal Society B: Biological Sciences 285:20181877. doi: 10.1098/rspb.2018.1877

Daniali L et al. (2013) Telomeres shorten at equivalent rates in somatic tissues of adults. Nature Communications 4:1597. doi: 10.1038/ncomms2602

Dantzer B, Fletcher QE (2015) Telomeres shorten more slowly in slow-aging wild animals than in fast-aging ones. Experimental Gerontology 71:38-47. doi: 10.1016/j.exger.2015.08.012

De Punder K, Heim C, Przesdzing I, Wadhwa PD, Entringer S (2018) Characterization in humans of in vitro leucocyte maximal telomerase activity capacity and association with stress. Philosophical Transactions of the Royal Society B: Biological Sciences 373. doi: 10.1098/rstb.2016.0441 10.6084/m9

Delignette-Muller M-L, Dutang C ( 2015) Fitdistrplus: An R package for fitting distributions. Journal of Statistical Software 64:1-34

Eisenberg DTA (2016) Telomere length measurement validity: the coefficient of variation is invalid and cannot be used to compare quantitative polymerase chain reaction and Southern blot telomere length measurement techniques. International Journal of Epidemiology:dyw191. doi: 10.1093/ije/dyw191

Fairlie J, Holland R, Pikington JG, Pemberton JM, Harrington L, Nussey DH (2016) Lifelong leukocyte telomere dynamics and survival in a free-living mammal. Aging Cell 15:140-148

Gil D, Alfonso-Iñiguez S, Pérez-Rodríguez L, Muriel J, Monclús R (2019) Harsh conditions during early development influence telomere length in an altricial passerine: Links with oxidative stress and corticosteroids. Journal of Evolutionary Biology 32:111-125. doi: 10.1111/jeb.13396

Gomes NMV, Shay JW, Wright WE (2010) Telomere biology in Metazoa. FEBS Letters 584:37413751. doi: 10.1016/j.febslet.2010.07.031

Gorbunova V, Bozzella MJ, Seluanov A (2008) Rodents for comparative aging studies: from mice to beavers. Age 30:111-119. doi: 10.1007/s11357-008-9053-4

Grosbellet E et al. (2015) Circadian desynchronization triggers premature cellular aging in a diurnal rodent. The FASEB Journal 29:4794-4803. doi: 10.1096/fj.14-266817

Harris SE et al. (2016) Longitudinal telomere length shortening and cognitive and physical decline in later life: The Lothian Birth Cohorts 1936 and 1921. Mechanisms of Ageing and Development 154:43-48. doi: 10.1016/j.mad.2016.02.004

Haussmann MF, Longenecker AS, Marchetto NM, Juliano SA, Bowden RM (2012) Embryonic exposure to corticosterone modifies the juvenile stress response, oxidative stress and telomere length. Proceedings of the Royal Society B: Biological Sciences 279:1447-1456. doi: 10.1098/rspb.2011.1913

Haussmann MF, Winkler DW, Huntington CE, Nisbet ICT, Vleck CM (2004) Telomerase Expression Is Differentially Regulated in Birds of Differing Life Span. Annals of the New York Academy of Sciences 1019:186-190. doi: 10.1196/annals.1297.029

Heidinger BJ, Blount JD, Boner W, Griffiths K, Metcalfe NB, Monaghan P (2012) Telomere length in early life predicts lifespan. Proceedings of the National Academy of Sciences 109:1742-1748. doi: 10.1073/pnas.1113306109

Hoelzl F, Cornils JS, Smith S, Moodley Y, Ruf T (2016a) Telomere dynamics in free-living edible dormice (Glis glis): the impact of hibernation and food supply. The Journal of Experimental Biology 219:2469-2474. doi: 10.1242/jeb.140871 
454

455

456

457

458

459

460

461

462

463

464

465

466

467

468

469

470

471

472

473

474

475

476

477

478

479

480

481

482

483

484

485

486

487

488

489

490

491

492

493

494

495

496

497

Hoelzl F, Smith S, Cornils JS, Aydinonat D, Bieber C, Ruf T (2016b) Telomeres are elongated in older individuals in a hibernating rodent, the edible dormouse (Glis glis). Scientific Reports 6:36856. doi: 10.1038/srep36856

Hothorn T, Bretz F, Westfall P, Heiberger RM (2008) Multcomp: simultaneous inference for general linear hypotheses. $R$ package version, 1-0.

Huchon D, Steppan SJ, Schenk JJ (2017) Muroid rodent phylogenetics: 900-species tree reveals increasing diversification rates. Plos One 12:e0183070. doi: 10.1371/journal.pone.0183070

Ilmonen P, Kotrschal A, Penn DJ (2008) Telomere attrition due to infection. Plos One 3:e2143. doi: 10.1371/journal.pone.0002143.t001

Kotrschal A, Ilmonen P, Penn DJ (2007) Stress impacts telomere dynamics. Biology Letters 3:128-130. doi: 10.1098/rsbl.2006.0594

Lê S, Josse J, Husson F (2008) FactoMineR: An R Package for Multivariate Analysis. Journal of Statistical Software 25:2-18

Martin-Ruiz CM, Gussekloo J, Van Heemst D, Von Zglinicki T, Westendorp RGJ (2005) Telomere length in white blood cells is not associated with morbidity or mortality in the oldest old: a population-based study. Aging Cell 4:287-290

Nettle D, Bateson M (2017) Detecting telomere elongation in longitudinal datasets: analysis of a proposal by Simons, Stulp and Nakagawa. PeerJ 5:e3265. doi: 10.7717/peerj.3265

Nettle D, Monaghan P, Gillespie R, Brilot B, Bedford T, Bateson M (2015) An experimental demonstration that early-life competitive disadvantage accelerates telomere loss. Proceedings of the Royal Society B: Biological Sciences 282:20141610-20141610. doi: 10.1098/rspb.2014.1610

Nettle D, Seeker LA, Nussey D, Froy H, Bateson M (2019) Consequences of measurement error in qPCR telomere data: A simulation study. PloS one 14:e0216118. doi: 10.1101/491944

Nowack J, Tarmann I, Hoelzl F, Smith S, Giroud S, Ruf T (2019) Always a price to pay: hibernation at low temperatures comes with a trade-off between energy savings and telomere damage. Biology Letters 15:20190466. doi: 10.1098/rsbl.2019.0466

Olonikov AM (1973) A theory of marginotomy. J Theor Biol. 41:181-190

Olsson M, Wapstra E, Friesen C (2018) Ectothermic telomeres: it's time they came in from the cold. Philosophical Transactions of the Royal Society B: Biological Sciences 373:20160449. doi: 10.1098/rstb.2016.0449

Pfaffl MW (2001) A new mathematical model for relative quantification in real-time RT-PCR. Nucleic Acids Research 29:2003-2007

Quirici V, Guerrero CJ, Krause JS, Wingfield JC, Vásquez RA (2016a) The relationship of telomere length to baseline corticosterone levels in nestlings of an altricial passerine bird in natural populations. Frontiers in Zoology 13. doi: 10.1186/s12983-016-0133-5

Quirici V, Guerrero CJ, Krause JS, Wingfield JC, Vásquez RA (2016b) The relationship of telomere length to baseline corticosterone levels in nestlings of an altricial passerine bird in natural populations. Frontiers in Zoology 13:1. doi: 10.1186/s12983-016-0133-5

Reichert S, Stier A (2017) Does oxidative stress shorten telomeres in vivo? A review. Biology Letters 13:20170463. doi: 10.1098/rsbl.2017.0463

Reichert $S$ et al. (2014) Increased brood size leads to persistent eroded telomeres. Frontiers in Ecology and Evolution 2. doi: 10.3389/fevo.2014.00009 
498

499

500

501

502

503

504

505

506

507

508

509

510

511

512

513

514

515

516

517

518

519

520

521

522

523

524

525

526

527

528

529

530

531

532

533

534

535

536

537

538

539

540

541
Rimbach R, Blanc S, Zahariev A, Gatta M, Pillay N, Schradin C (2018a) Seasonal variation in energy expenditure in a rodent inhabiting a winter-rainfall desert. Journal of Comparative Physiology B. doi: 10.1007/s00360-018-1168-z

Rimbach R, Jäger J, Pillay N, Schradin C (2018b) Food Availability Is the Main Driver of Seasonal Changes in Resting Metabolic Rate in African Striped Mice (Rhabdomys pumilio). Physiological and Biochemical Zoology 91:826-833. doi: 10.1086/696828

Rimbach R, Pillay N, Schradin C (2016) Both thyroid hormone levels and resting metabolic rate decrease in African striped mice when food availability decreases. The Journal of Experimental Biology. doi: 10.1242/jeb.151449

Salomons HM, Mulder GA, van de Zande L, Haussmann MF, Linskens MHK, Verhulst S (2009) Telomere shortening and survival in free-living corvids. Proceedings of the Royal Society B: Biological Sciences 276:3157-3165. doi: 10.1098/rspb.2009.0517

Schradin C (2008a) Differences in prolactin levels between three alternative male reproductive tactics in striped mice (Rhabdomys pumilio). Proceedings of the Royal Society of London B 275:1047-1052

Schradin C (2008b) Seasonal changes in testosterone and corticosterone levels in four social categories of a desert dwelling sociable rodent. Horm \& Behav 53:573-579

Schradin C (2008c) Seasonal changes in testosterone and corticosterone levels in four social classes of a desert dwelling sociable rodent. Hormones and Behavior 53:573-579. doi: 10.1016/j.yhbeh.2008.01.003

Schradin C, König B, Pillay N (2010) Reproductive competition favours solitary living while ecological constraints impose group-living in African striped mice. Journal of Animal Ecology 79:515-521

Schradin C et al. (2012) Social flexibility and social evolution in mammals: a case study of the African striped mouse (Rhabdomys pumilio). Molecular Ecology 21:541-553. doi: 10.1111/j.1365-294X.2011.05256.x

Schradin C, Pillay N (2005) Demography of the striped mouse (Rhabdomys pumilio) in the succulent karoo: a unique population in an extreme environment. Mammalian Biology 70:84-92

Schradin C, Pillay N, Bertelsmeier C (2019) Social flexibility and environmental unpredictability in African striped mice. Behavioral Ecology and Sociobiology 73:94

Schradin C, Raynaud J, Arrivé M, Blanc S (2014) Leptin levels in free ranging striped mice (Rhabdomys pumilio) increase when food decreases: the ecological leptin hypothesis. General and Comparative Endocrinology 206:139-145. doi: 10.1016/j.ygcen.2014.06.024

Seeker LA et al. (2018) Longitudinal changes in telomere length and associated genetic parameters in dairy cattle analysed using random regression models. Plos One 13:e0192864. doi: 10.1371/journal.pone.0192864

Seluanov A et al. (2007) Telomerase activity coevolves with body mass, not lifespan. Aging Cell 6:45-52

Simons MJP (2015) Questioning causal involvement of telomeres in aging. Ageing Research Reviews. doi: 10.1016/j.arr.2015.08.002

Simons MJP, Stulp G, Nakagawa S (2014) A statistical approach to distinguish telomere elongation from error in longitudinal datasets. Biogerontology 15:99-103. doi: 10.1007/s10522-013-9471-2 
542

543

544

545

546

547

548

549

550

551

552

553

554

555

556

557

558

559

560

561

562

563

564

565

566

567

568

569

570

571

572

573

574

575

576

577

578

579

580

581

582

583

584

585

Smith S, Turbill C, Penn DJ (2011) Chasing telomeres, not red herrings, in evolutionary ecology. Heredity 107:372-373. doi: 10.1038/hdy.2011.14

Spurgin LG et al. (2018) Spatio-temporal variation in lifelong telomere dynamics in a long-term ecological study. Journal of Animal Ecology 87:187-198. doi: 10.1111/1365-2656.12741

Steenstrup T, Hjelmborg JvB, Kark JD, Christensen K, Aviv A (2013) The telomere lengthening conundrum--artifact or biology? Nucleic Acids Research 41:e131-e131. doi: $10.1093 /$ nar/gkt370

Stier A et al. (2014) Starting with a handicap: phenotypic differences between early- and lateborn king penguin chicks and their survival correlates. Functional Ecology 28:601-611. doi: $10.1111 / 1365-2435.12204$

Tian $X$ et al. (2018) Evolution of telomere maintenance and tumour suppressor mechanisms across mammals. Philosophical Transactions of the Royal Society B: Biological Sciences 373:20160443. doi: 10.1098/rstb.2016.0443 10.6084/m9

Tissier ML, Williams TD, Criscuolo F (2014) Maternal Effects Underlie Ageing Costs of Growth in the Zebra Finch (Taeniopygia guttata). Plos One 9:e97705. doi: 10.1371/journal.pone.0097705

Turbill C, Ruf T, Smith S, Bieber C (2013) Seasonal variation in telomere length of a hibernating rodent. Biology Letters 9:20121095-20121095. doi: 10.1098/rsbl.2012.1095

Turbill C, Smith S, Deimel C, Ruf T (2012) Daily torpor is associated with telomere length change over winter in Djungarian hamsters. Biology Letters 8:304-307. doi: 10.1098/rsbl.2011.0758

Vera E, Bernardes de Jesus B, Foronda M, Flores Juana M, Blasco Maria A (2012) The Rate of Increase of Short Telomeres Predicts Longevity in Mammals. Cell Reports 2:732-737. doi: 10.1016/j.celrep.2012.08.023

Verhulst S, Aviv A, Benetos A, Berenson GS, Kark JD (2013) Do leukocyte telomere length dynamics depend on baseline telomere length? An analysis that corrects for 'regression to the mean'. European Journal of Epidemiology 28:859-866. doi: 10.1007/s10654-0139845-4

Viblanc VA et al. (2018) Maternal oxidative stress and reproduction: Testing the constraint, cost and shielding hypotheses in a wild mammal. Functional Ecology 32:722-735. doi: $10.1111 / 1365-2435.13032$

Vitikainen EIK et al. (2016) Evidence of Oxidative Shielding of Offspring in a Wild Mammal. Frontiers in Ecology and Evolution 4. doi: 10.3389/fevo.2016.00058

Vuarin P, Pillay N, Schradin C (2019) Elevated basal corticosterone levels increase disappearance risk of light but not heavy individuals in a long-term monitored rodent population. Hormones and Behavior 113:95-102

Whittemore K, Vera E, Martínez-Nevado E, Sanpera C, Blasco MA (2019) Telomere shortening rate predicts species life span. Proceedings of the National Academy of Sciences 116:15122-15127. doi: 10.1073/pnas.1902452116

Wolak ME, Fairbairn DJ, Paulsen YR (2012) Guidelines for estimating repeatability. Methods in Ecology and Evolution 3:129-137. doi: 10.1111/j.2041-210X.2011.00125.x

Young AJ (2018) The role of telomeres in the mechanisms and evolution of life-history trade-offs and ageing. Philosophical Transactions of the Royal Society B: Biological Sciences 373:20160452. doi: 10.1098/rstb.2016.0452 
586

587

588 